\title{
A Conserved Alternative Splice in the von Recklinghausen Neurofibromatosis (NF1) Gene Produces Two Neurofibromin Isoforms, Both of Which Have GTPase-Activating Protein Activity
}

\author{
LONE B. ANDERSEN, ${ }^{1}$ ROYMARIE BALLESTER,${ }^{2}$ DOUGLAS A. MARCHUK, ${ }^{1}$ ERIC CHANG ${ }^{2}$ \\ DAVID H. GUTMANN, ${ }^{1}$ ANN M. SAULINO,${ }^{1}$ JACQUES CAMONIS, ${ }^{2}$ \\ MICHAEL WIGLER, ${ }^{2}$ AND FRANCIS S. COLLINS ${ }^{1}$ \\ Howard Hughes Medical Institute and the Departments of Internal Medicine and Human Genetics, \\ University of Michigan, Ann Arbor, Michigan 48109, ${ }^{1}$ and Cold Spring Harbor \\ Laboratory, Cold Spring Harbor, New York $11724^{2}$
}

Received 26 June 1992/Returned for modification 25 August 1992/Accepted 1 October 1992

\begin{abstract}
Sequence analysis has shown significant homology between the catalytic regions of the mammalian ras GTPase-activating protein (GAP), yeast Ira1p and Ira2p (inhibitory regulators of the RAS-cyclic AMP pathway), and neurofibromin, the protein encoded by the $N F 1$ gene. Yeast expression experiments have confirmed that a 381-amino-acid segment of neurofibromin, dubbed the GAP-related domain (GRD), can function as a GAP. Using the RNA polymerase chain reaction with primers flanking the NF1-GRD, we have identified evidence for alternative splicing in this region of the NF1 gene. In addition to the already published sequence (type I), an alternative RNA carrying a 63-nucleotide insertion (type II) is present in all tissues examined, although the relative amounts of types I and II vary. The insertion is conserved across species but is not present in GAP, IRA1, or IRA2. GenBank searches have failed to identify significant similarity between the inserted sequence and known DNA or protein sequences, although the basic amino acid composition of the insertion shares features with nuclear targeting sequences. Expression studies in yeasts show that despite the partial disruption of the neurofibromin-IRA-GAP homology by this insertion, both forms of the NF1-GRD can complement loss of IRA function. In vivo assays designed to compare the GAP activity of the two alternatively spliced forms of the NF1-GRD show that both can increase the conversion of GTP-bound ras to its GDP-bound form, although the insertion of the 21 amino acids weakens this effect. The strong conservation of this alternative splicing suggests that both type I and II isoforms mediate important biological functions of neurofibromin.
\end{abstract}

von Recklinghausen neurofibromatosis (type 1 neurofibromatosis, NF1) is an autosomal dominant disorder affecting 1 in 3,000 to 4,000 newborns of which 30 to $50 \%$ are estimated as possessing spontaneous mutations $(11,27)$. Hallmarks of the disorder are the presence of café-au-lait spots, neurofibromas, axillary and inguinal freckling, Lisch nodules (iris hamartomas), orthopedic abnormalities, and optic glioma. The manifestations of the disorder are extremely variable, even within the same family. A variety of other manifestations including cognitive impairment, seizures, and megalencephaly, and malignancies can also be present.

The gene for NF1 was identified recently on chromosome $17(9,42,44)$ by using the chromosome translocation breakpoints of two unique NF1 patients to pinpoint the gene. The NF1 transcript was shown to be large $(\sim 13 \mathrm{~kb})$ and ubiquitously expressed (44). Several lines of evidence indicate that the NF1 phenotype is caused by inactivation of the normal gene product and that the NF1 gene may be a tumor suppressor gene: all the mutations identified within the gene so far (translocations [42, 44], deletions [41, 42], point mutations [8], and a de novo insertion [43, 44]) are consistent with an inactivation mechanism. Furthermore, an NF1 patient with a deletion of part of proximal $17 q$ including the NF1 gene, in which the deleted fragment exists as a mini-

\footnotetext{
* Corresponding author.
}

chromosome, has been identified (2). The fact that the minichromosome is lost constitutionally from $6 \%$ of somatic cells, leaving those cells hemizygous at the NF1 locus, supports the hypothesis that the mechanism by which the NF1 gene functions is actually recessive at the cellular level (2). Even more supportive of the tumor suppressor hypothesis is the documentation of homozygous inactivation of the NF1 gene in a malignant nerve sheath tumor from an NF1 patient (20). Somatic mutations have also been found in the NF1 gene in colon adenocarcinoma, astrocytoma, and peripheral blood from patients with myelodysplastic syndrome (21). Further evidence in support of the hypothesis that $N F 1$ is a tumor suppressor gene is the finding that malignant neurofibrosarcoma cells do not produce functional full-length neurofibromin (7). The fact that the NF1 gene is expressed in all tissues analyzed so far by RNA polymerase chain reaction (PCR) (44) suggests that other gene products interact with neurofibromin to define the predilection of the disease for the neural crest.

Initial analysis of the carboxy-terminal portion of the NF1 gene failed to show homology with known DNA or protein sequences. cDNA walking efforts have since resulted in cloning of the entire $N F 1$ transcript coding region $(23,47)$, resulting in demonstration of homology between the NFI protein and mammalian ras GTPase-activating protein (GAP) and also with the yeast equivalents Ira1p and Ira2p (inhibitory regulators of the RAS-cyclic AMP pathway) (4, 


$\begin{array}{lcccccccc}0 & 1000 & 2000 & 3000 & 4000 & 5000 & 6000 & 7000 & 8000 \\ \text { nucleotides } & 1 & 1 & 1 & \perp & 1 & 1 & 1\end{array}$

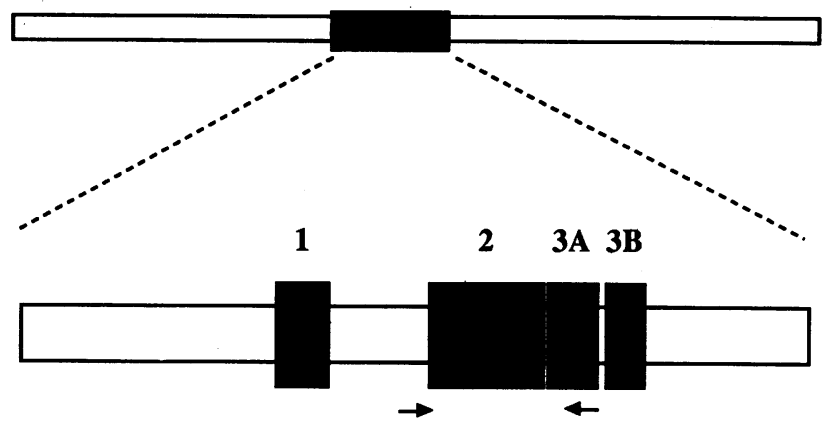

NFI GAP-related domain

FIG. 1. The translated region and the GAP-related domain of the $N F 1$ gene. Shown to scale in the upper part of the figure is the translated region of the $N F 1$ gene, with the filled rectangle indicating the GAP-related domain (NF1-GRD). Below, nucleotides 3582 to 4823 (23) encompassing the NF1-GRD are shown in an expanded fashion. The filled rectangles labeled 1 through $3 B$ correspond to the blocks of sequence homology between neurofibromin, Ira1p, Ira2p, and GAP (45). The arrows indicate the positions of the primers used to amplify by PCR a region of the NFI-GRD, as described in the text.

47). Further extensive quantitative sequence analysis of neurofibromin, GAP, and the Ira proteins has revealed 17 homology blocks common to neurofibromin, Iralp, and Ira2p (4). Of these 17 blocks, only 4 show homology to GAP as well (45) (Fig. 1), thereby narrowing the estimate of the GAP catalytic domain. This GAP-related domain of the NF1 gene product has been named NF1-GRD.

In Saccharomyces cerevisiae, Iralp and Ira2p are involved in the regulation of the RAS signal transduction pathway controlling cell growth and differentiation (34-36). Ira1p and Ira2p are both capable of catalyzing the conversion of yeast RAS-GTP to RAS-GDP; in fact, this catalytic function has been demonstrated to lie in a 381-amino-acid central domain of Ira2p, which closely correlates with the region of sequence homology between GAP and neurofibromin (35). This domain of both GAP and neurofibromin is able to complement yeast ira mutant strains as shown by the observation that expression of this domain of GAP or neurofibromin in ira 1 and ira 2 mutants suppresses the heat shock sensitivity phenotype characteristic of these strains. The catalytic domains of GAP and neurofibromin have also been shown to stimulate GTPase activity of wild-type human Ha-ras protein when both are expressed in yeasts $(4,5,35$, 46) or in a baculovirus system (24). Neither GAP nor neurofibromin appears to be able to catalyze GTPase activity of mutant Ha-ras Val-12 in biochemical assays $(4,25,35)$, though neurofibromin differs from GAP in being able to induce temperature sensitivity when overexpressed in mutant $c d c 25$ Ha-ras ${ }^{\text {Val-12 }}$ strains, suggesting that neurofibromin carries some ability to inhibit mutant Ha-ras Val-12 protein (4).

We have previously reported preliminary evidence for unexpected alternative splicing involving the NF1-GRD (1), and two other reports have provided evidence for differential expression of the two types of the NF1-GRD transcripts in undifferentiated versus differentiated neuronal cells (26) and in brain tumors versus normal brain tissue (33). In this report, we demonstrate that this alternative splice is unique to $N F 1$ but conserved widely across vertebrates and describe the results of yeast expression and GAP assays of the alternative product, indicating that it retains GAP activity.

\section{MATERIALS AND METHODS}

RNA extraction. Extraction of total cellular RNA from the solid tissues used for this study was performed with guanidinium thiocyanate followed by centrifugation through a cesium chloride cushion (29). Cytoplasmic RNA was extracted from all the cell lines in the presence of Vanadyl Ribonucleoside Complex (Bethesda Research Laboratories) as previously described (8).

PCR analysis. Total RNA $(0.2 \mu \mathrm{g})$ from each tissue sample was reverse transcribed with CAT-RT, a primer $3^{\prime}$ of the $N F 1-G R D$ for analysis of NF1 (5'-CAGCTTTGGAAGTC), or with oligo(dT) for analysis of GAP. Samples were then amplified by 35 cycles of PCR with $1 \mathrm{~min}$ at $94^{\circ} \mathrm{C}, 1 \mathrm{~min}$ at $65^{\circ} \mathrm{C}$, and $2 \mathrm{~min}$ at $72^{\circ} \mathrm{C}$ for all primers. Primers amplifying the 303- and 366-bp type I/II products of the NF1 gene were 5'-ATTGTGATCACATCCTCTGATTGG for the amino terminus and 5'-ATCTAAAATCCCTGCTTCATACGG for the carboxy terminus. Primers amplifying the $1,243-$ and 1,306-bp products of the $N F 1$ region were 5'-CATCAAGCT TGTGCGCAAACAGGTGGCAGGAAAC for the amino terminus and 5'-CATGCCGCGGTCAGTGTGTATCTGCCA CAGGTTTG for the carboxy terminus. These latter primers included either a HindIII site (amino terminus) or a SacII site (carboxy terminus) plus an additional $4 \mathrm{bp}$ at the $5^{\prime}$ end for digestion and cloning purposes. Primers amplifying the 243-bp product of GAP were 5'-AACATACTTTCAGAGCT TGTGGAG for the amino terminus and 5'-CAGTGTTCT TGCAGCAATAGGAGA for the carboxy terminus. These primers were placed in regions of GAP with $100 \%$ identity between the human and the bovine sequence (39).

Sequence analysis. Double-stranded sequencing of the PCR products cloned into pBluescript was performed by the dideoxy chain termination method (30) with the Sequenase kit, version 2 (United States Biochemical Corporation).

Yeast media, manipulations, and nomenclature. Saccharomyces cerevisiae yeast strains were grown in YPD $(2 \%$ peptone, $1 \%$ yeast extract, $2 \%$ glucose) or in synthetic medium $(0.67 \mathrm{~g}$ of yeast nitrogen base per liter, $2 \%$ glucose, and appropriate auxotrophic supplements). Standard yeast genetic methods were followed as described previously (32). The lithium acetate method was used for transformation of yeast cells (18). Wild-type alleles and dominant mutations are denoted by capital letters, recessive mutations are given in lowercase italicized letters, and gene disruptions are shown by lowercase letters, which represent the disrupted gene, followed by two codons and the auxotrophic gene marker used for the disruption. Gene disruptions are abbreviated by lowercase italicized letters representing the mutated gene.

Plasmids. The type I and II 303- and 366-bp PCR products from human, mouse, and chicken NF1 RNA were directly cloned into pBluescript by the T-vector approach (22). Sequences of the clones were determined by dideoxy sequencing of both strands.

The 1,306-bp NF1-GRD was amplified by PCR with primers containing HindIII (amino terminus) and SacII (carboxy terminus) sites and initially cloned into pBluescript for blue-white color selection. Four individual PCR clones were subsequently digested with HindIII and SacII and ligated 
with the yeast expression vector pADANS, cut with the same enzymes, thereby creating pADANS-NF1-5, -6, -12, and -19 . The vector pADANS (4) is a derivative of pADNS (10). It contains the LEU2 gene, a HpaI-HindIII fragment from the $2 \mu \mathrm{m}$ circle including the origin of replication, a SspI-EcoRI fragment containing the ampicillin resistance gene from the plasmid pUC18, a EcoRI-HindIII fragment containing the promoter and the first 14 codons of the $S$. cerevisiae $A D H 1$ gene, and a HindIII-Bam HI fragment containing the $A D H 1$ terminator sequences. A polylinker containing unique HindIII and SacII sites separates the promoter and the terminator.

The plasmid pADGAP contains the entire coding region of the human GAP gene on a high-copy-number $L E U 2$ plasmid containing the $A D H 1$ promoter and terminator sequences, pAD4 $\Delta(5)$. The YepPDE2 plasmid contains the yeast $P D E 2$ gene on a high-copy-number LEU2 plasmid, YEp13 (31). The $P D E 2$ gene encodes a high-affinity cyclic AMP phosphodiesterase.

The plasmid p1F7 was constructed by inserting a BamHI fragment that contains the human Ha-ras cDNA into the vector PGK2F5. The Bam HI fragment containing the Ha-ras cDNA was obtained by digesting the plasmid pAHRG-H1 (5) with the HindIII enzyme, adding Bam HI linkers, and cloning into the BglII site of the PGK2F5 plasmid. The plasmid p1F12.9 was constructed in the same way as p1F7, except that it contains the mutant Ha-ras ${ }^{\mathrm{Val}-12}$ isolated form the plasmid pAHRV-H2 (5). The PGK2F5 plasmid contains the TRP1 gene, the URA3 gene, and the phosphoglycerokinase $(P G K)$ promoter followed by a $B g l I I$ site used for cloning purposes and also contains the terminator sequences of the $P G K$ gene. The PGK2F5 plasmid was constructed as follows: a BglII-SphI fragment from plasmid Yrp7 (40) containing the TRP1 gene without the adjacent autonomously replicating sequence (ARS) sequence was cloned into the BamHI-SphI sites of PGKYi2, creating PGK2F5. PGKYi2 was constructed by inserting the HindIII fragment of plasmid $\mathrm{pEMBLYe} 30 / 2$ containing a $P G K$ promoter-terminator cassette (6) in the HindIII site of plasmid pEMBLYi31 (3).

Yeast strains. The yeast strain IR2.53 (MATa his3 leu2 ura3 trp1 ade8 ira1::HIS3 ira2::ADE8) containing disruptions in the IRA1 and the IRA2 genes was constructed in two steps. First, the $I R A 2$ gene was disrupted as previously described (4) by using a BamHI fragment containing the $A D E 8$ gene as an auxotrophic marker. This results in a deletion of the $5^{\prime}$ coding sequences of the IRA2 gene as well as the catalytic domain. To carry out gene replacement experiments, the yeast haploid auxotrophic strain SP1 was transformed with a SalI-digested plasmid containing the deleted IRA2 gene, and transformants were selected for adenine prototrophy. The resulting strain, IRA2.5 (MATa his3 leu2 ura3 trp1 ade8 ira2::ADE8) was transformed with an $X b a I$ fragment containing a deletion in the IRA1 gene. In this plasmid (5), the HIS 3 gene is inserted into the BglII sites of the IRA1 gene. This results in a $3.2-\mathrm{kb}$ deletion that includes the catalytic domain of IRAI, leaving the 5 ' coding sequences intact. The resulting transformants were selected for histidine prototrophy. Southern hybridization analysis was used to verify that both the IRAI and the IRA2 genes were replaced by the disrupted genes.

The yeast strains J1041F7 (MATa his3 leu 2 ura3 trp1 ade8 pde2::HIS3 trp1::pTRP1 URA3 Ha-ras) and J1041F12 (MATa his3 leu2 ura3 trp1 ade8 pde2::HIS3 trp1::pTRP1 URA3 Ha-ras ${ }^{\text {Val-12 }}$ ) were constructed by transforming the strain J104 (MATa his3 leu2 ura3 trp1 ade8 pde2::HIS3) (25) with the plasmids p1F7 and p1F12.9, respectively, after digestion with the enzyme $X b a I$, selecting for uracil prototrophy. This leads to the integration of the plasmid into the TRPI locus.

Heat shock sensitivity assay. Heat shock sensitivity was determined as described previously $(31,37)$. Yeast strains were transformed with various plasmids containing the LEU2 gene and plated onto SC-Leu (synthetic complete minus Leu) plates. Independent transformants were patched onto SC-Leu plates and incubated at $30^{\circ} \mathrm{C}$ for 2 days. Heat shock was performed by replica plating cells to a plate preheated for $1 \mathrm{~h}$ at $55^{\circ} \mathrm{C}$ and then by a 10 -min incubation at $55^{\circ} \mathrm{C}$. After heat shock treatment, the plates were incubated at $30^{\circ} \mathrm{C}$ for 2 days and photographed.

GAP assays and quantitation. Yeast strains were grown to saturation in $5 \mathrm{ml}$ of selective media and then diluted in 200 $\mathrm{ml}$ of YPD media. Cultures were grown for $12 \mathrm{~h}$, and cells were harvested by centrifugation. Cell pellets were resuspended in buffer $\mathrm{A}(20 \mathrm{mM}$ Tris- $\mathrm{HCl}[\mathrm{pH} 7.5], 50 \mathrm{mM} \mathrm{NaCl}$, $5 \mathrm{mM} \mathrm{MgCl}{ }_{2}$ ) with $1 \%$ Nonidet $\mathrm{P}-40,1 \mu \mathrm{g}$ (each) of aprotinin and pepstatin per $\mathrm{ml}$, and $1 \mathrm{mM}$ phenylmethylsulfonyl fluoride. The cells were lysed by vortexing in Eppendorf tubes containing glass beads. The lysates were centrifuged for 2 min at $4^{\circ} \mathrm{C}$ in an Eppendorf centrifuge, and the supernatant was used in the GAP assays.

GAP assays were performed as reported elsewhere (38). Purified Ha-rasp21 $(0.07 \mu \mathrm{M})(16)$ was prebound to GTP by incubation for $30 \mathrm{~min}$ at $30^{\circ} \mathrm{C}$ in buffer $\mathrm{B}(20 \mathrm{mM}$ Tris$\mathrm{HCl}$ [pH 7.5], $20 \mathrm{mM} \mathrm{NaCl}, 2.5 \mathrm{mM} \mathrm{MgCl}$ ) with 0.025 $\mu \mathrm{M}\left[\alpha^{-32} \mathrm{P}\right] \mathrm{GTP}(3,000 \mathrm{mCi} / \mathrm{mmol}$; New England Nuclear), $1 \mathrm{mM}$ ATP, and $1 \mathrm{mg}$ of bovine serum albumin per $\mathrm{ml}$ in a volume of $40 \mu \mathrm{l}$. The cell lysates, $0.4 \mathrm{mg}$ in $20 \mu \mathrm{l}$, were incubated with $1 \mu$ l of p21 prebound to GTP for $30 \mathrm{~min}$ at room temperature. The samples were then diluted to $200 \mu \mathrm{l}$ with buffer $A$ and incubated for $30 \mathrm{~min}$ at $4^{\circ} \mathrm{C}$ with $2 \mu \mathrm{g}$ of monoclonal antibody Y13-259 (13) followed by incubation with rabbit anti-rat immunoglobulin and protein A-Sepharose for $1 \mathrm{~h}$ at $4^{\circ} \mathrm{C}$. Immunoprecipitates were washed with buffer $\mathrm{A}$, and the nucleotides were eluted from p21 by incubation with $10 \mu \mathrm{l}$ of $1 \%$ sodium dodecyl sulfate (SDS) and $20 \mathrm{mM}$ EDTA for $5 \mathrm{~min}$ at $65^{\circ} \mathrm{C}$. A total of $2 \mu \mathrm{l}$ of eluted nucleotides was resolved by chromatography on polyethyleneimine-impregnated cellulose plates in $0.75 \mathrm{M} \mathrm{KH}_{2} \mathrm{PO}_{4}$, $\mathrm{pH}$ 4.0. The chromatography plates were subjected to autoradiography, and the labeled nucleotides were scraped off the plates and counted in scintillation fluid.

Analysis of the guanine nucleotide bound to RAS. The analysis was performed essentially as previously described (14). Yeast cells expressing human Ha-ras under the control of the $P G K$ promoter (strain J1041F7) were grown to an $A_{600}$ of 0.6 to 1.0 in selective media. Cells were collected and incubated in $10 \mathrm{ml}$ of SD-P media with $1 \mathrm{mCi}$ of ${ }^{32} \mathrm{P}_{\mathrm{i}}$ (NEN-Dupont) for $3 \mathrm{~h}$. The cultures were collected by centrifugation and washed once with $40 \mathrm{ml}$ of water. The pellets were resuspended in $1 \mathrm{ml}$ of cold lysis buffer containing $50 \mathrm{mM}$ Tris- $\mathrm{HCl}$ (pH 7.4), $20 \mathrm{mM} \mathrm{MgCl}_{2}, 100 \mathrm{mM} \mathrm{NaCl}$, $0.5 \%$ (vol/vol) Nonidet P-40, $1 \mathrm{mM}$ phenylmethylsulfonyl fluoride, and $1 \mu \mathrm{g}$ (each) of leupeptin and aprotinin per $\mathrm{ml}$ and disrupted by vortexing with glass beads. The lysates were centrifuged for $15 \mathrm{~min}$ at $4^{\circ} \mathrm{C}$ in an Eppendorf centrifuge, and the supernatants containing $1.0 \times 10^{8} \mathrm{cpm}$ of trichloroacetic acid-insoluble radioactivity were subjected to immunoprecipitation as described above for the GAP assays. The nucleotides were eluted and resolved as described above, and the chromatography plates were exposed to $\mathrm{X}$-ray film for quantitation by densitometry (Bioimage Corporation, Ann Arbor, Mich.) or direct quantitative measure- 
ment with the Fujix BAS2000 Bio-imaging Analyzer. The percent GTP of total guanine nucleotides was calculated from these analyses by assuming uniform ${ }^{32} \mathrm{P}$ labeling of all phosphates and by correcting for the moles of phosphate per mole of guanosine.

\section{RESULTS}

PCR of the NF1-GRD. By using RNA PCR with primers as indicated in Fig. 1, an alternative product involving the NF1-GRD was identified. In addition to amplification of the expected 303-bp product (type I) according to the known sequence $(23,47)$, a larger band (type II) was seen when RNA from several normal and pathologic human tissues including kidney, spleen, lung, colon, muscle, brain, peripheral nerve, an Epstein-Barr virus-transformed lymphoblastoid cell line, HeLa cells, and a melanoma cell line as shown in Fig. 2A was amplified. This was also observed in RNA from stomach, skin fibroblasts, HepG2 (hepatoma cell line), HEL (erythroleukemia cell line), HT29 (colon cancer cell line), NF88-3 (neurofibrosarcoma cell line), neuroblastoma, thymoma, breast carcinoma, and neurofibroma (data not shown). Some variation in the relative amounts of types I and II was seen from tissue to tissue. However, the quantitative significance of this variation is uncertain, since some variation also was seen when the reverse transcription and PCR reaction of the same RNA sample were repeated. Subsequent PCR of reverse-transcribed RNA from mouse, chicken, rat, and bovine sources showed a similar additional larger product (Fig. 2B). The successful amplification of cDNA from such diverse species with PCR primers derived from the human sequence is an indication of the high degree of evolutionary conservation of this domain of $N F 1$.

Sequence analysis of type II NF1-GRD. The larger amplified products from human lung, kidney, and an Epstein-Barr virus-transformed lymphoblastoid cell line were cloned into pBluescript. Sequence analysis (Fig. 3) of two individual clones from each tissue sample showed that in all of them, an in-frame insertion of $63 \mathrm{bp}$ was present at nucleotide position $3108(47)$ or position 4321 (23). This places the insertion in block 2, a region of strong homology between GAP, Iralp, Ira2 $p$, and neurofibromin (45). In fact, the insertion significantly weakens the statistical significance of this homology block. Thirty-three of 63 nucleotides are adenine, and thus the inserted protein sequence is rich in basic amino acids, with 5 of 21 amino acids being lysine and 1 being histidine. Comparison of this DNA and protein sequence with the entries in GenBank failed to show significant similarity with known sequences. The additional sequence $(1,243 \mathrm{bp}$ [see below]) of the RNA PCR product surrounding the inserted $63 \mathrm{bp}$ of the type II product showed a perfect match with the published type I sequence. Furthermore, an oligomer corresponding to the inserted $63 \mathrm{bp}$ was shown to hybridize to a $\sim 500$-kb yeast artificial chromosome containing the entire NF1 catalytic region (data not shown), indicating that the inserted exon arises from this same locus. Taken together, this indicates that the type II RNA originates from the same locus by alternative splicing and is not the product of a different locus.

Similarly, the PCR-amplified type I and II products from mouse and chicken cDNAs were cloned into pBluescript, and two individual clones from each were sequenced. Outside the insertion, the mouse and chicken sequences show strong homology to that of humans (mouse, 93.7\%, and chicken, $84.5 \%$ ). Both show an insertion of $63 \mathrm{bp}$ in the type II form at the same nucleotide position and with an almost

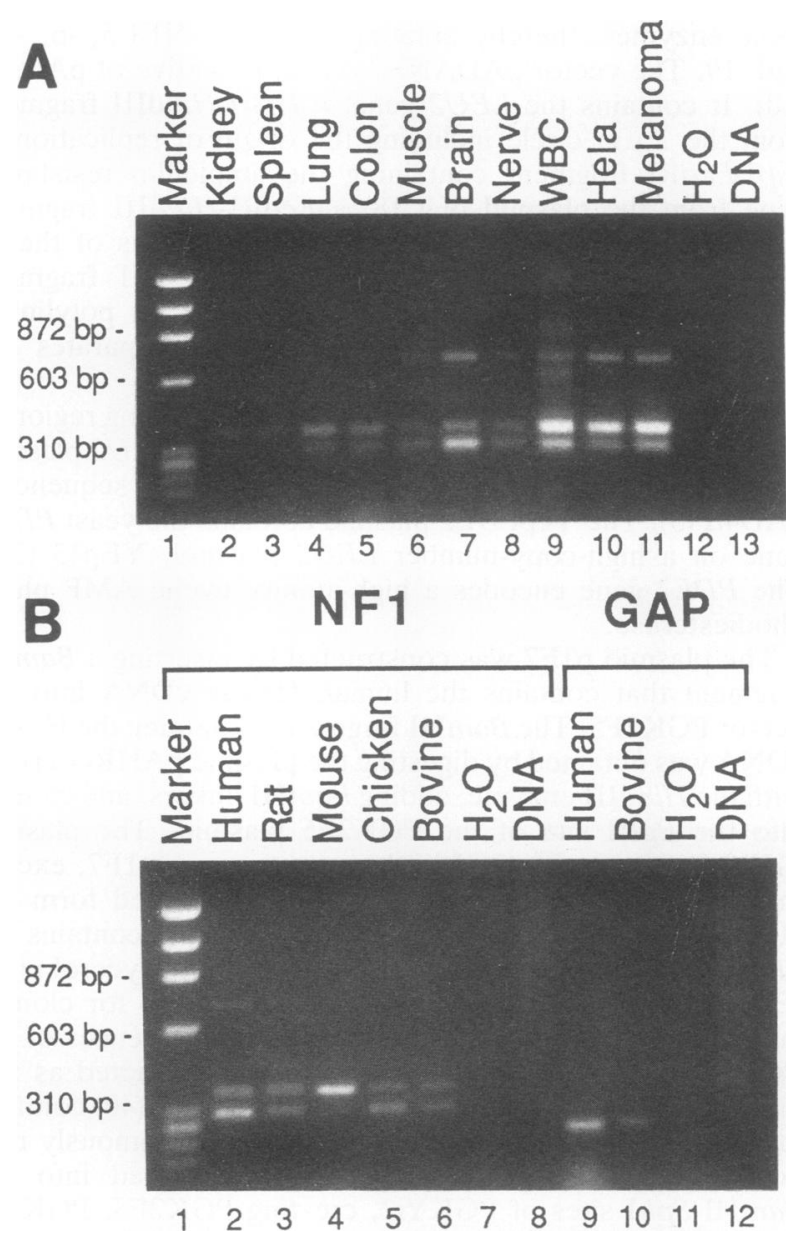

FIG. 2. (A) RNA PCR identifies two alternative products of the NF1-GRD. RNA from several human tissues was reverse transcribed with CAT-RT, a primer $3^{\prime}$ of the NF1-GRD, and submitted to 35 cycles of PCR $\left(1 \mathrm{~min}\right.$ at $94^{\circ} \mathrm{C}, 1 \mathrm{~min}$ at $65^{\circ} \mathrm{C}$, and $2 \mathrm{~min}$ at $72^{\circ} \mathrm{C}$ ) with the primers shown in Fig. 1. In all tissues examined, two PCR products were present, one at the expected size of $303 \mathrm{bp}$ and the other at $366 \mathrm{bp}$. The larger band in some lanes is presumed to be a heteroduplex. When the reverse transcription and the PCR of the same RNA samples were repeated, different amounts of the two products were seen, thereby making comparison of the relative amounts of the two products between different tissues difficult. No bands were seen when DNA was amplified (lane 13), suggesting that the primers are located in two different exons separated by a significant distance. The marker lane (lane 1) contains the HaellI fragments of $\phi X 174$ RF DNA (Bethesda Research Laboratories). (B) The alternative form of the NF1-GRD is conserved across species. RNA from human brain, rat PC12 pheochromocytoma cells, mouse kidney, chicken brain, and bovine choroid plexus (lanes 2 to 6) was reverse transcribed with CAT-RT and submitted to PCR as for panel A. Again, two PCR products were seen, showing that the identified alternative splicing is conserved across species. The fact that both the reverse transcription primer and the two PCR primers are designed from the known human sequence and yet still are able to amplify cDNA from other species under relatively stringent conditions is indicative of a high degree of nucleotide conservation among the different species. In another experiment, RNAs from human leukocytes and bovine retina (lanes 9 and 10) were reverse transcribed with oligo(dT) and submitted to PCR with primers flanking the potential site of a similar insertion in the GAP gene $\left(35\right.$ cycles, $1 \mathrm{~min}$ at $94^{\circ} \mathrm{C}, 1 \mathrm{~min}$ at $65^{\circ} \mathrm{C}, 2 \mathrm{~min}$ at $72^{\circ} \mathrm{C}$ ). This time only a PCR product of $243 \mathrm{bp}$, the expected size according to the published sequence (39), was seen. Included in each experiment were DNA and water controls. 


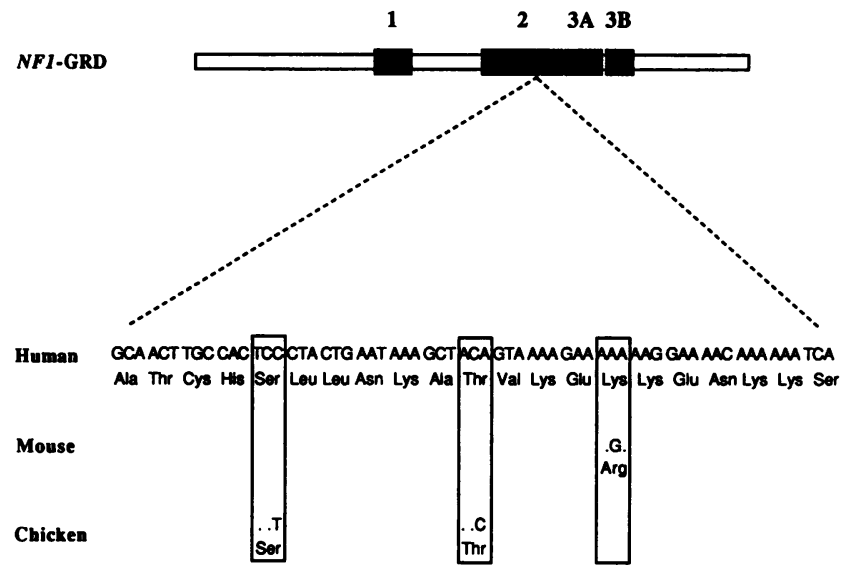

FIG. 3. Position and sequence of the inserted 63 nucleotides. Sequence analysis showed that an in-frame insertion of 63 nucleotides is present in type II RNA at nucleotide position 4321 of the $N F 1$ gene (23). This places the insertion in block 2 as indicated. The sequence shows strong conservation across species.

identical nucleotide composition as in humans (Fig. 3). In mouse sequences there is an A-to-G substitution at nucleotide position 44 within the insertion resulting in a conservative lysine-to-arginine substitution in the protein product. In chicken sequences, two silent nucleotide substitutions are present.

PCR analysis of the GAP catalytic domain. The genomic sequences of yeast IRAI and IRA2 are known and are colinear with the cDNAs, thereby providing evidence that such an alternative isoform does not occur in either of these genes $(34,36)$. To determine whether such an alternative product was present in GAP, we designed GAP-specific primers flanking the predicted site of the insertion (39). RNA PCR revealed only one band of the expected size in both human and bovine RNA (Fig. 2B), indicating that the occurrence of alternative splicing in this conserved domain is unique to $N F 1$.

Construction of the $N F 1$ expression vector. To obtain data regarding the functional significance of the 63-bp insertion in the NF1-GRD, we amplified by PCR a region from EpsteinBarr virus-transformed lymphoblastoid cDNA containing the complete NF1-GRD from amino acids 1124 to 1538 (23). The type II product was cloned into pBluescript, and four independent PCR clones were subsequently subcloned into the yeast expression vector pADANS, giving rise to pADANS-NF1-5, pADANS-NF1-6, pADANS-NF1-12, and pADANS-NF1-19. Complete sequencing of the inserts of two of the four clones (pADANS-NF1-5 and pADANS-NF119) showed a nucleotide difference at position 3491 of one of the published sequences (47) in both clones, which results in an amino acid change from alanine to glycine. This C-to-G change is in full agreement with the sequence obtained in our laboratory from a type I cDNA clone isolated from a fetal brain library (Stratagene, catalog number 936206) (23) and may therefore reflect either an error in the original published sequence or a polymorphism. Likewise, at nucleotide position 2547 (47) a silent nucleotide change from $C$ to $G$ was present in pADANS-NF1-5, in pADANS-NF1-19, and in two type I cDNA clones isolated from the fetal brain library. The sequence was otherwise in agreement with the published sequence and demonstrated the 63-bp insertion.

Complementation of ira mutant strains by NF1-GRD types

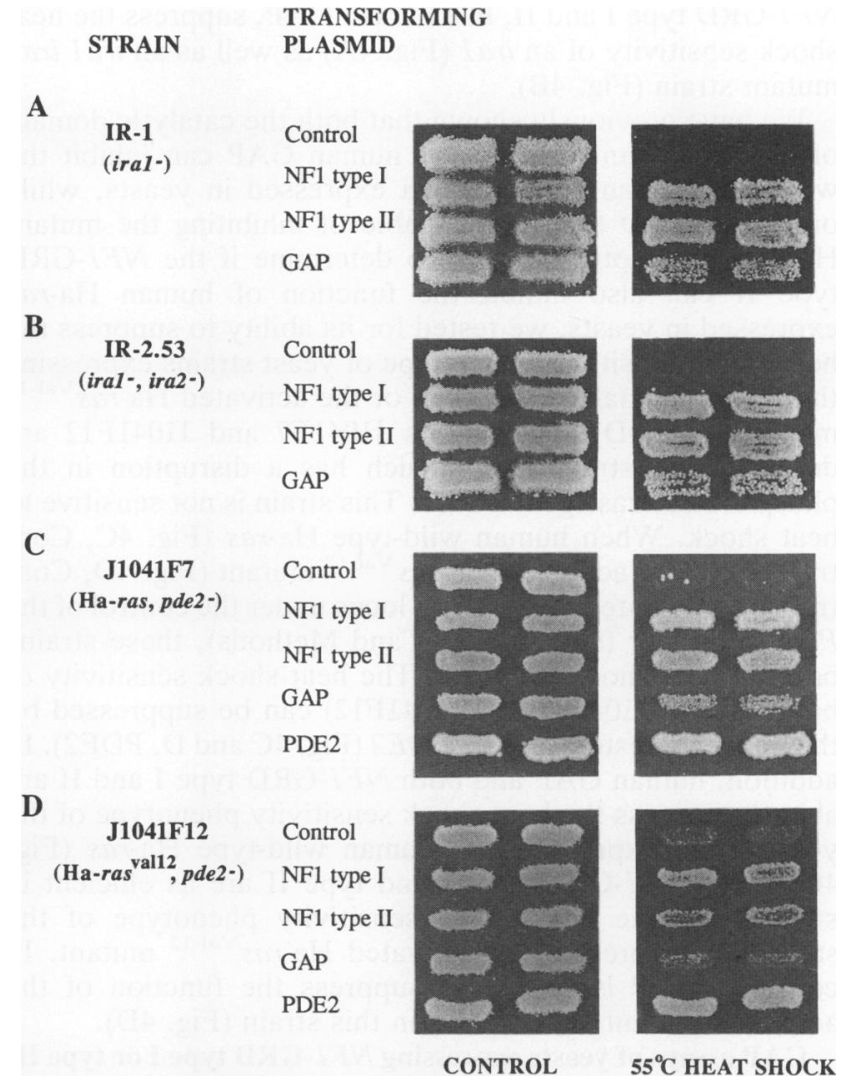

FIG. 4. Effects of expressing NFI-GRD type I and type II on the heat shock sensitivity of strains lacking the IRAI and the IRA2 genes and strains expressing wild-type or activated human ras genes. Yeast strains (see Materials and Methods) were transformed with plasmids containing the LEU2 gene and selected on SC-Leu plates. Independent transformants were patched onto SC-Leu plates and incubated at $30^{\circ} \mathrm{C}$ for 2 days, replica plated onto SC-Leu plates, and heat shocked at $55^{\circ} \mathrm{C}$ for $10 \mathrm{~min}$. After heat shock treatment, the plates were incubated at $30^{\circ} \mathrm{C}$ for 2 days. The strains were transformed with a control plasmid, pADANS; a plasmid containing the NF1-GRD type I catalytic fragment, pADANS-NF1 type I; a plasmid expressing the NF1-GRD type II, pADANS-NF1 type II; a plasmid expressing the entire coding sequence of the human GAP gene, pADGAP; or a plasmid expressing the phosphodiesterase gene $P D E 2$, YepPDE2.

I and II. As mentioned in the Introduction, the $I R A 1$ and IRA2 gene products of $S$. cerevisiae downregulate RAS activity by stimulating its GTPase activity. Deletion of either IRA1 or IRA2 results in sensitivity to heat shock like that of yeast cells expressing RAS2 $2^{\text {Val-19. }}$. It has been previously shown that GAP and the catalytic domain of neurofibromin (type I) are both able to complement loss of IRA function and suppress the heat shock sensitivity phenotype when expressed in ira mutant strains $(4,5,24,35,46)$. On the other hand, neither GAP nor the type I NF1-GRD can inhibit the mutationally activated RAS2 $2^{\mathrm{al}-19}$, as indicated by lack of suppression of the heat shock sensitivity. In this yeast strain, only expression of the $P D E 2$ gene, which encodes the high-affinity cyclic AMP phosphodiesterase, can suppress the heat shock sensitivity phenotype.

To determine if the 21-amino-acid insertion has an effect on the activity of the NF1-GRD, we tested for the ability of NF1-GRD type II to suppress the heat shock sensitivity phenotype of ira mutant strains. As shown in Fig. 4, both 
NF1-GRD type I and II, like human GAP, suppress the heat shock sensitivity of an iral (Fig. 4A) as well as an iral ira2 mutant strain (Fig. 4B).

We have previously shown that both the catalytic domain of neurofibromin (type I) and human GAP can inhibit the wild-type human Ha-ras when expressed in yeasts, while only NF1-GRD type I is capable of inhibiting the mutant Ha-ras ${ }^{\text {Val-12 }}$ protein $(4,5)$. To determine if the NF1-GRD type II can also inhibit the function of human Ha-ras expressed in yeasts, we tested for its ability to suppress the heat shock sensitivity phenotype of yeast strains expressing the wild-type Ha-ras (Fig. 4C) or the activated Ha-ras ${ }^{\text {Val-12 }}$ mutant (Fig. 4D). The strains J1041F7 and J1041F12 are derived from strain $\mathrm{J} 104$, which has a disruption in the phosphodiesterase gene $P D E 2$. This strain is not sensitive to heat shock. When human wild-type Ha-ras (Fig. 4C, Control) or human activated Ha-ras ${ }^{\text {Val-12 }}$ mutant (Fig. 4D, Control) are integrated in the TRP1 locus under the control of the $P G K$ promoter (see Materials and Methods), these strains become heat shock sensitive. The heat shock sensitivity of both strains (J1041F7 and J1041F12) can be suppressed by the phosphodiesterase gene $P D E 2$ (Fig. $4 \mathrm{C}$ and $\mathrm{D}$, PDE2). In addition, human GAP and both NF1-GRD type I and II are able to suppress the heat shock sensitivity phenotype of the yeast strain expressing the human wild-type Ha-ras (Fig. 4C). Both NF1-GRD type I and type II are as efficient in suppressing the heat shock sensitivity phenotype of the strain that expresses the activated Ha-ras ${ }^{\text {Val-12 }}$ mutant. In contrast, GAP is unable to suppress the function of the activated mutant Ha-ras ${ }^{\text {Val-12 }}$ in this strain (Fig. 4D).

GAP assays of yeasts expressing NF1-GRD type I or type II. We have shown previously that lysates prepared from cells expressing the type I NF1-GRD protein stimulate the GTPase activity of human wild-type Ha-ras, although to a lesser extent than human GAP (4). Lysates from yeasts expressing GAP or NF1-GRD type I are not capable of accelerating the hydrolysis of GTP by the activated human Ha-ras ${ }^{\mathrm{Val}-12}$. In order to compare the GTPase-stimulating activity of the two alternative forms of the NF1-GRD, we prepared lysates from an iral ira2 mutant strain (strain IR2.53; see Materials and Methods) transformed with either a control plasmid or plasmids expressing NF1-GRD type I, NF1-GRD type II, or human GAP and tested these for their abilities to increase the GTPase activity of purified human wild-type Ha-ras. As shown in Table 1, compared with control lysates, GTP hydrolysis was increased by incubation of Ha-ras with $0.4 \mathrm{mg}$ of lysates from yeasts expressing GAP or NF1-GRD type I. In contrast, lysates prepared from yeasts expressing NF1-GRD type II were not capable of increasing the GTPase activity of Ha-ras. In lysates prepared from yeasts expressing GAP or NF1-GRD type I, some increase in GTPase activity of Ha-ras is still detected even when only $0.04 \mathrm{mg}$ of total protein is assayed. Western blot (immunoblot) analysis with a polyclonal antibody raised to a peptide derived from the published sequence (17) showed that the difference in the ability of the extracts to stimulate the GTPase activity is not due to a difference in the amount of NF1-GRD protein expressed, since both extracts from each independent experiment contain the same amount of NF1-GRD (data not shown).

In vivo determination of the amount of Ha-ras bound to GTP in radiolabeled yeast cells expressing NF1-GRD type I and type II. As shown in Table 1, yeast extracts prepared from strains expressing NF1-GRD type II show no detectable GTPase-stimulating activity. To determine if the inability of the NF1-GRD type II to increase the GTPase activity
TABLE 1. Ha-ras GTPase stimulation by yeast lysates ${ }^{a}$

\begin{tabular}{|c|c|c|c|c|}
\hline \multirow{2}{*}{$\begin{array}{c}\text { Expt }^{b} \text { and } \\
\text { protein }(m g)\end{array}$} & \multicolumn{4}{|c|}{ Proportion of $\mathrm{p}^{2} 1^{\text {ras }}$ bound to GTP } \\
\hline & Control & NF1 type I & NF1 type II & GAP \\
\hline \multicolumn{5}{|l|}{1} \\
\hline 0.04 & 0.63 & 0.52 & 0.63 & 0.51 \\
\hline 0.40 & 0.64 & 0.23 & 0.60 & 0.14 \\
\hline \multicolumn{5}{|l|}{2} \\
\hline 0.04 & 0.62 & 0.58 & 0.64 & 0.44 \\
\hline 0.40 & 0.65 & 0.16 & 0.65 & 0.10 \\
\hline
\end{tabular}

${ }^{a}$ Wild-type human Ha-ras protein prelabeled with $\left[{ }^{32} \mathrm{P}\right] \mathrm{GTP}$ was incubated for $30 \mathrm{~min}$ at room temperature with either $0.04 \mathrm{mg}$ or $0.4 \mathrm{mg}$ of yeast extracts of the ira1 ira 2 mutant yeast strain IR2.53 transformed with the control plasmid pADANS; the plasmid expressing the NF1-GRD type I, pADANSNF1 type I; the plasmid expressing the NF1-GRD type II, pADANS-NF1 type II; or the plasmid expressing the human GAP gene, pADGAP. The Ha-ras protein was then immunoprecipitated with the monoclonal antibody Y13-259 and incubated with rabbit anti-rat immunoglobulin and protein A-Sepharose. The labeled nucleotides were eluted and resolved by thin-layer chromatography (see Materials and Methods). The chromatography plates were subjected to autoradiography and the spots were scraped and counted in scintillation fluid.

${ }^{b}$ Two separate experiments were performed with independently prepared lysates.

of Ha-ras in vitro is also reflected in intact cells, we determined the amount of Ha-ras bound to guanine nucleotides in strains expressing the wild-type human Ha-ras under the control of the PGK promoter (J1041F7) and transformed with a control plasmid or plasmids expressing the NF1-GRD type I and type II, GAP, or the phosphodiesterase gene PDE2 (Fig. 5; Table 2). Cell extracts from the yeast strains were prepared, Ha-ras protein was immunoprecipitated, and the guanine nucleotide bound to Ha-ras was analyzed as described in Materials and Methods (Fig. 5; Table 2). The autoradiogram in Fig. 5 shows that in intact cells expressing the NFI-GRD type I or type II, the amount of human Ha-ras bound to GTP is reduced compared with either the control strain or the strain expressing the PDE2 gene. In addition, expression of human GAP also leads to a decrease in the GTP-bound Ha-ras, as has been previously

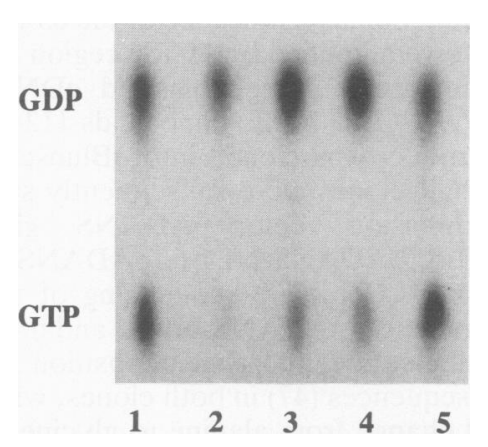

FIG. 5. Autoradiograph of the guanine nucleotides bound to Ha-ras in strains expressing NF1-GRD type I and type II. Yeast strains expressing wild-type Ha-ras under the $P G K$ promoter (strain J1041F7 [see Materials and Methods]) and transformed with pADANS, the control plasmid (lane 1), pADANS-NF1 type I (lane 2), pADANS-NF1 type II (lane 3), pADGAP (lane 4), and YepPDE2 (lane 5) were labeled with ${ }^{32} \mathrm{P}_{\mathrm{i}}$ for $3 \mathrm{~h}$, and Ha-ras was immunoprecipitated as described under Materials and Methods. The labeled nucleotides were eluted and resolved by thin-layer chromatography. Shown is the autoradiograph of the plate exposed to X-ray film; results of the quantitation of the plate are shown in Table 2, experiment 1 . 
TABLE 2. Guanine nucleotide bound to Ha-ras in yeast cells ${ }^{a}$

\begin{tabular}{lccccc}
\hline \multirow{2}{*}{ Expt } & \multicolumn{5}{c}{ Proportion of protein bound with GTP } \\
\cline { 2 - 6 } & PDE2 & Vector & GAP & NF1 type I & NF1 type II \\
\hline $1^{b}$ & 0.51 & 0.39 & 0.13 & 0.02 & 0.13 \\
2 & 0.34 & 0.27 & 0.07 & 0.04 & 0.03 \\
3 & & 0.26 & 0.11 & 0.00 & 0.06 \\
4 & & 0.27 & 0.14 & 0.00 & 0.09 \\
5 & & 0.26 & 0.05 & 0.01 & 0.05 \\
Avg & & 0.29 & 0.10 & 0.01 & 0.07 \\
\hline
\end{tabular}

${ }^{a}$ Human Ha-ras was immunoprecipitated from radiolabeled yeast cells transformed with the phosphodiesterase gene $P D E 2$, the vector plasmid, NF1 type I, NF1 type II, or human GAP, respectively, as described in the legend to Fig. 5 and Materials and Methods. The bound guanine nucleotides were eluted and resolved by thin-layer chromatography. The chromatography plates were exposed to X-ray film for quantitation by densitometry (experiments 1 and 2) or direct quantitative measurement with the Fujix BAS2000 Bio-imaging Analyzer (experiments 3 to 5). The results are presented as the proportion of total counts recovered as GTP from the Ha-ras proteins. The difference between NF1 type I and NF1 type II is significant at the $P=0.05$ level (two-tailed Student's $t$ test for paired varieties).

$b$ The autoradiograph shown in Fig. 5 is derived from this experiment.

shown (35). That the reduction of the amount of GTP-bound Ha-ras is dependent on the expression of proteins that have GTPase-stimulating activity and not proteins that in general suppress the heat shock sensitivity phenotype of this strain is shown by the amount of GTP-bound Ha-ras in strains transformed with the phosphodiesterase gene $P D E 2$, which is comparable to that of the control strain (Table 2). In contrast to the results obtained in vitro, the results in Table 2 show that compared with the control and the strain expressing $P D E 2$, the amount of GTP-bound Ha-ras is reduced in intact cells expressing the NF1-GRD type I, type II, and GAP, suggesting that in vivo the type II NF1-GRD might have GTPase-stimulating activity. In analyzing the results of five independent experiments, cells expressing the NF1-GRD type II have consistently more Ha-ras bound to GTP than cells expressing NF1-GRD type I.

\section{DISCUSSION}

Multiple examples of alternative splicing have been described previously in the eukaryotic molecular biology literature (19). The combinatorial advantages of shuffling exons in and out of a protein product and the opportunity to utilize one gene for several different functions have been noted, although in only a few instances is definitive information available about the precise functions of alternatively spliced products of the same gene. The development of the PCR and its application to RNA analysis will undoubtedly expand the recognition of the alternative splicing process, since it facilitates the identification of small differences in transcripts which would be more difficult to detect by Northern (RNA) blotting.

The NF1 gene is large and complex, stretching across approximately $300 \mathrm{~kb}$ of genomic DNA (23), encoding a transcript of $13 \mathrm{~kb}(44)$, and made up of a large number of exons, the boundaries of most of which have not yet been completely identified. One other potential example of alternative splicing of $N F 1$ has previously been identified near the carboxy-terminal end by the comparison of two cDNA clones (9). The alternative splice event described in this report, however, is of particular interest because it falls within a central domain of the NF1 molecule where there is the most information about function, namely, the catalytic domain responsible for stimulating conversion of ras-GTP to ras-GDP. The catalytic activity of this domain of neurofibromin has been previously postulated by sequence comparisons and subsequently confirmed by genetic and biochemical experiments $(4,24,46,47)$. It is fair to say, however, that this is unlikely to be the only function of neurofibromin, as the protein itself is quite large $(2,818$ amino acids), and this catalytic function can be expressed by using only about $10 \%$ of the coding region from the central portion of the molecule. Demonstration of colocalization of neurofibromin with microtubules suggests an additional possible role for the NF1 gene product in intracellular signal transduction pathways (15a). Of further note is the significant additional homology between neurofibromin, Iralp, and Ira2p on the carboxyterminal side of this catalytic domain, which implies an evolutionarily shared additional function, the nature of which remains elusive. An attractive option would be that this part of the molecule is responsible for some sort of effector function.

The additional $63 \mathrm{bp}$ in the type II transcript undoubtedly reflects the insertion of a separate exon by alternative splicing. The striking evolutionary conservation of the type II form, which is true both for the precise positioning as well as the sequence of the encoded 21 additional amino acids, strongly supports the conclusion that the presence of both of these two forms is functionally important. Sequence analysis of the effect of this insertion on the homology between NF1 and other GAPs suggested that the type II form might no longer possess biological activity. This conclusion has been ruled out by the yeast expression experiments and analysis of the guanine nucleotide bound to Ha-ras in yeast cells. In heat shock assays, the NFI type I and type II are both equally effective in inhibiting the function of the yeast RAS genes as well as the wild-type $\mathrm{Ha}$-ras and mutant $\mathrm{Ha}$ ras $^{\text {Val-12 }}$ (Fig. 4). The ability of the NF1 type II isoform to inhibit the function of the mutant Ha-ras ${ }^{\mathrm{Val}-12}$ suggests that the type II product binds to this activated form with affinity similar to that of the NF1 type I, since the ability of the NF1-GRD to inhibit the function of activated Ha-ras ${ }^{\text {Val-12 }}$ does not depend on its ability to increase its GTPase activity. However, a difference is noted in in vitro biochemical assays of the yeast extracts expressing NF1-GRD types I and II. In contrast to extracts containing type I, extracts prepared from cells expressing NF1 type II (Table 1), under conditions in which there are comparable amounts of both types I and II present, lack apparent GTPase-stimulating activity with Ha-ras. This result suggests that the 21-amino-acid insertion results in a decrease in the catalytic activity of NF1 type II and it remains a formal (but unlikely) possibility that the biological activity of the type II form derives from some mechanism other than GTPase activation. Results from in vivo determination of the guanine nucleotide bound to Ha-ras in intact cells (Fig. 5 and Table 2) show that both isoforms can decrease the amount of GTP bound to Ha-ras, although the effect of type II is slightly lower. The discrepancy between these two results might be due to the fact that although both assays measure related functions (ras-GTP hydrolysis), they are not equivalent. In vitro, the concentration of Ha-ras (3.5 nM) is probably much higher than the concentration of the NF1-GRD. Under these conditions, as has been shown previously (24), the NF1-GRD is saturated with respect to p21-GTP ras, so that the low activity measured reflects the catalytic properties and not the binding affinity. In intact cells, NF1-GRD is expressed in a multicopy plasmid and under the control of the $A D H 1$ promoter, conditions which ensure high levels of expression. Under 
these conditions the NF1-GRD is probably in excess of the amount of p21 ras, and this results in an apparent increase in the catalytic activity of the NF1-GRD. Therefore, in the yeast strains overexpressing NF1-GRD, the differences in the catalytic potencies of the NF1 type I and type II will be minimized. Another aspect that has to be considered is that the insertion of the 21 amino acids in the catalytic domain can result in an increase in the binding affinity for p21 ras. Neither the in vitro assay nor the assay in intact cells allow us to assess this possibility. Resolution of this possibility will await a more detailed biochemical and kinetic characterization of the two proteins.

Using RNA PCR analysis, we have not been able to detect evidence thus far of consistent tissue specificity differences of type I and II RNA in a variety of normal and abnormal tissues. In fact, at least some evidence of both forms has been found in all tissues analyzed. Interestingly, however, one study indicates that the type I transcript is predominantly expressed in normal brain tissue, whereas the type II transcript predominates in brain tumors (33). However, another study indicates that the type I transcript is predominantly expressed in undifferentiated cells, whereas the type II transcript predominates in differentiated cells (25). This group also noted a change in expression pattern in SH-SY5Y neuroblastoma cells from predominantly type I to type II NF1-GRD mRNA when these cells were induced by retinoic acid to differentiate in a neuronal direction. It is thus conceivable that the type II mRNA, through interaction with as yet unknown cellular molecules, functions as a switch in cellular differentiation.

There are at least four other possible functional explanations for the occurrence of the type I and type II forms and their evolutionary conservation across at least 200 million years. The first possibility, namely, that the insertion to create the type II form represents a way of generating an $N F 1$ protein without GAP catalytic function, seems to have been ruled out by the experiments reported herein. A second possibility is that the type I and type II catalytic domains are qualitatively different in some important way, perhaps in the efficiency with which they interact differently with various members of the ras family of proteins. This will require further investigation with K-ras, N-ras, R-ras, and K-rev-1. A third possibility, and one which has been partially supported by the experiments here, is that there is a quantitative difference in the catalytic function of the type I and type II products. It should be noted that the assays we have used in this study might not be a true reflection of the mammalian system, in which the amounts of both proteins (ras and neurofibromin) will be more comparable and under regulatory control. It is also conceivable that the analysis of the type I and II forms might yield a different result if studied in the full-length proteins as opposed to in the catalytic domains.

A fourth possibility is that the 21-amino-acid insertion in the type II form generates an isoform with a totally different function in addition to its GAP activity. In this regard, it is noteworthy that the amino acid sequence of the insertion is highly basic and shares some sequence similarities with the nuclear localization signals that have been defined for a large number of proteins $(12,15,28)$. It is not currently possible to define a completely accurate consensus sequence for such nuclear localization signals, and the proof or disproof of such a suggestion rests with a mutational analysis and a determination of the ability of this sequence to target a heterologous protein to the nucleus. It is certainly not clear why it would be advantageous to target any part of neurofibromin to the nucleus, but our present stage of knowledge about the complete array of functions of this large protein is sufficiently superficial that the notion should not be discounted. Whichever additional function this alternative exon might convey to the molecule, it appears to be unique to NFI when compared with other known GAP-like molecules.

The importance of the type I and type II forms in the pathogenesis of neurofibromatosis also remains to be elucidated. In general, mutations identified thus far in the gene have been located in the carboxy-terminal half of the protein, though this is at least in part a reflection of ascertainment bias due to earlier availability of $3^{\prime} \mathrm{cDNA}$ sequences $(9,43,44)$. Most of these mutations would be expected to produce truncated versions of both the type I and II isoforms, although these may well be unstable. It will be of interest to look specifically for NF1 mutations in the 63-bp alternate exon to assess the effects on phenotype. Alternately, the specific disruption of the type II form by homologous recombination in mice should be feasible and might also shed light on the relative importance and function of this alternative form.

\section{ACKNOWLEDGMENTS}

We thank Manju Swaroop for help in subcloning and Rork Kuick for assistance with densitometry.

This work was supported by grant 1523410 from the National Institutes of Health to F.S.C. F.S.C. is an Investigator and L.B.A. is an Associate of the Howard Hughes Medical Institute. M.W. is an American Cancer Society Research Professor.

\section{REFERENCES}

1. Andersen, L., R. Ballester, D. Marchuk, A. Saulino, M. Wigler, and F. Collins. 1991. Alternative splicing in the proposed catalytic domain of the type 1 neurofibromatosis gene, abstr. A98. Abstr. 8th Int. Congr. Hum. Genet. Am. J. Hum. Genet. 49(Suppl.):21.

2. Andersen, L. B., N. Tommerup, and J. Koch. 1990. Formation of a minichromosome by excision of the proximal region of $17 \mathrm{q}$ in a patient with von Recklinghausen neurofibromatosis. Cytogenet. Cell Genet. 53:206-210.

3. Baldari, C., and G. Cesareni. 1985. Plasmids pEMBLY: new single-stranded shuttle vectors for the recovery and analysis of yeast DNA sequences. Gene 35:27-32.

4. Ballester, R., D. Marchuk, M. Boguski, A. Saulino, R. Letcher, M. Wigler, and F. Collins. 1990. The NF1 locus encodes a protein functionally related to mammalian GAP and yeast IRA proteins. Cell 63:851-859.

5. Ballester, R., T. Michaeli, K. Ferguson, H.-P. Xu, F. McCormick, and M. Wigler. 1989. Genetic analysis of mammalian GAP expressed in yeast. Cell 59:681-686.

6. Banroques, J., A. Delahodde, and C. Jacq. 1986. A mitochondrial RNA maturase gene transferred to the yeast nucleus can control mitochondrial mRNA splicing. Cell 46:837-844.

7. Basu, T. N., D. H. Gutmann, J. A. Fletcher, T. W. Glover, F. S. Collins, and J. Downward. 1992. Aberrant regulation of ras proteins in malignant cells from type 1 neurofibromatosis patients. Nature (London) 356:713-715.

8. Berger, S. L., and C. S. Birkenmeier. 1979. Inhibition of intractable nucleases with ribonucleoside-vanadyl complexes: isolation of messenger ribonucleic acid from resting lymphocytes. Biochemistry 18:5143-5149.

9. Cawthon, R. M., R. Weiss, G. Xu, D. Viskochil, M. Culver, J. Stevens, M. Robertson, D. Dunn, R. Gesteland, P. O'Connell, and $\mathbf{R}$. White. 1990. A major segment of the neurofibromatosis type 1 gene: cDNA sequence, genomic structure, and point mutations. Cell 62:193-201.

10. Colicelli, J., C. Birchmeier, T. Michaeli, K. O'Neill, M. Riggs, and $M$. Wigler. 1989. Isolation and characterization of a mammalian gene encoding a high-affinity cAMP phosphodiesterase. Proc. Natl. Acad. Sci. USA 86:3599-3603. 
11. Crowe, F. W., W. T. Schull, and J. F. Neel. 1956. A clinical, pathological, and genetic study of multiple neurofibromatosis. Charles C Thomas, Publisher, Springfield, Ill.

12. Dingwall, C., and R. A. Laskey. 1986. Protein import into the cell nucleus. Annu. Rev. Cell Biol. 2:367-390.

13. Furth, M., L. Davies, B. Fleurdelys, and E. Scolnick. 1982. Monoclonal antibodies to the p21 product of the transforming gene of Harvey sarcoma virus and of the cellular ras family. J. Virol. 43:294-304.

14. Gibbs, J. B., M. D. Schaber, M. S. Marshall, E. M. Scolnick, and I. S. Sigal. 1987. Identification of guanine nucleotides bound to ras-encoded proteins in growing yeast cells. Proc. Natl. Acad. Sci. USA 262:10426-10429.

15. Goldfarb, D. S. 1989. Nuclear transport. Curr. Opin. Cell Biol. 1:441-446.

15a.Gregory, P. E., D. H. Gutmann, and F. S. Collins. Unpublished data.

16. Gross, M., R. Sweet, G. Sathe, S. Yokoyama, O. Fasano, M. Goldfarb, M. Wigler, and M. Rosenberg. 1985. Characterization of human H-RAS proteins produced in Escherichia coli. Mol. Cell. Biol. 5:1015-1024.

17. Gutmann, D. H., D. L. Wood, and F. S. Collins. 1991. Identification of the neurofibromatosis type 1 gene product. Proc. Natl. Acad. Sci. USA 88:9658-9662.

18. Ito, H., Y. Fukuda, K. Murata, and A. Kimura. 1983. Transformation of intact yeast cells treated with alkaline cations. J. Bacteriol. 153:163-168.

19. Leff, S. E., M. G. Rosenfeld, and R. M. Evans. 1986. Complex transcriptional units: diversity in the regulation of gene expression by alternative RNA processing. Annu. Rev. Biochem. 55:1091-1117.

20. Legius, E., D. A. Marchuk, F. S. Collins, and T. W. Glover. Somatic deletion of the neurofibromatosis type 1 gene in a neurofibrosarcoma supports the tumor suppressor hypothesis. Submitted for publication.

21. Li, Y., G. Bollag, R. Clark, J. Stevens, L. Conroy, D. Fults, K. Ward, E. Friedman, W. Samowitz, M. Robertson, P. Bradley, F. McCormick, R. White, and R. Cawthon. 1992. Somatic mutations in the neurofibromatosis 1 gene in human tumors. Cell 69:275-281.

22. Marchuk, D., M. Drumm, A. Saulino, and F. S. Collins. 1991. Construction of T-vectors, a rapid and efficient system for cloning PCR products. Nucleic Acids Res. 19:1154.

23. Marchuk, D. A., A. M. Saulino, R. Tavakkol, M. Swaroop, M. R. Wallace, L. B. Andersen, A. L. Mitchell, D. H. Gutmann, M. Boguski, and F. S. Collins. 1991. cDNA cloning of the type 1 neurofibromatosis gene: complete sequence of the NF1 gene product. Genomics 11:931-940.

24. Martin, G. A., D. Viskochil, G. Bollag, P. C. McCabe, W. J. Crosier, H. Haubruck, L. Conroy, R. Clark, P. O'Connell, R. M. Cawthon, M. A. Innis, and F. McCormick. 1990. The GAPrelated domain of the neurofibromatosis type 1 gene product interacts with ras p21. Cell 63:843-849.

25. Nikawa, J., S. Cameron, T. Toda, K. M. Ferguson, and M. Wigler. 1987. Rigorous feedback control of cAMP levels in Saccharomyces cerevisiae. Genes Dev. 1:931-937.

26. Nishi, T., P. S. Y. Lee, K. Oka, V. A. Levin, S. Tanase, Y. Morino, and H. Saya. 1991. Differential expression of two types of the neurofibromatosis type 1 (NF1) gene transcripts related to neuronal differentiation. Oncogene 6:1555-1559.

27. Riccardi, V. M., and J. E. Eichner. 1986. Neurofibromatosis: phenotype, natural history, and pathogenesis, Johns Hopkins University Press, Baltimore.

28. Roberts, B. 1989. Nuclear location signal-mediated protein transport. Biochim. Biophys. Acta 1008:263-280.

29. Sambrook, J., E. F. Fritsch, and T. Maniatis. 1989. Molecular cloning: a laboratory manual, 2nd ed. Cold Spring Harbor Laboratory, Cold Spring Harbor, N.Y.

30. Sanger, F., S. Nicklen, A. R. Coulson. 1977. DNA sequencing with chain-terminating inhibitors. Proc. Natl. Acad. Sci. USA 74:5463-5467.
31. Sass, P., J. Field, J. Nikawa, T. Toda, and M. Wigler. 1986. Cloning and characterization of the high affinity cAMP phosphodiesterase of $S$. cerevisiae. Proc. Natl. Acad. Sci. USA 83:9303-9307.

32. Sherman, F., G. R. Fink, and J. B. Hicks. 1986. Laboratory course manual for methods in yeast genetics. Cold Spring Harbor Laboratory, Cold Spring Harbor, N.Y.

33. Suzuki, Y., H. Suzuki, T. Kayama, and S. Shibahara. 1991. Brain tumors predominantly express the neurofibromatosis type 1 gene transcript containing the 63 base insert in the region coding for GTPase activating protein-related domain. Biochem. Biophys. Res. Commun. 181:955-961.

34. Tanaka, K., K. Matsumoto, and A. Toh-e. 1989. IRA1, an inhibitory regulator of the RAS-cyclic AMP pathway in Saccharomyces cerevisiae. Mol. Cell. Biol. 9:757-768.

35. Tanaka, K., M. Nakafuko, T. Satoh, M. S. Marshall, J. B. Gibbs, K. Matsumoto, Y. Kaziro, and A. Toh-e. 1990. S. cerevisiae genes IRA1 and IRA2 encode proteins that may be functionally equivalent to mammalian ras GTPase activating protein. Cell 60:803-807.

36. Tanaka, K., M. Nakafuku, F. Tamanoi, Y. Kaziro, K. Matsumoto, and A. Toh-e. 1990. IRA2, a second gene of Saccharomyces cerevisiae that encodes a protein with a domain homologous to mammalian ras GTPase-activating protein. Mol. Cell. Biol. 10:4303-4313.

37. Toda, T., I. Uno, T. Ishikawa, S. Powers, T. Kataoka, D. Broek, S. Cameron, J. Broach, K. Matsumoto, and M. Wigler. 1985. In yeast, RAS proteins are controlling elements of adenylate cyclase. Cell 40:27-36.

38. Trahey, M., and F. McCormick. 1987. A cytoplasmic protein stimulates normal N-ras p21 GTPase, but does not affect oncogenic mutants. Science 238:542-545.

39. Trahey, M., G. Wong, R. Halenbeck, B. Rubinfeld, G. A. Martin, M. Ladner, C. M. Long, W. J. Crosier, K. Watt, K. Koths, and F. McCormick. 1988. Molecular cloning of two types of GAP complementary DNA from human placenta. Science 242:1697-1700.

40. Tschumper, G., and J. Carbon. 1980. Sequence of a yeast DNA fragment containing a chromosomal replicator and the TRPI gene. Gene 10:157-166.

41. Upadhyaya, M., A. Cheryson, W. Broadhead, A. Fryer, D. J. Shaw, S. Huson, M. R. Wallace, L. B. Andersen, D. A. Marchuk, D. Viskochil, D. Black, P. O'Connell, F. S. Collins, and P. S. Harper. 1990. A $90 \mathrm{~kb}$ DNA deletion associated with neurofibromatosis type 1. J. Med. Genet. 27:738-741.

42. Viskochil, D., A. M. Buchberg, G. Xu, R. M. Cawthon, J. Stevens, R. K. Wolfi, M. Culver, J. C. Carey, N. G. Copeland, N. A. Jenkins, R. White, and P. O'Connell. 1990. Deletions and a translocation interrupt a cloned gene at the neurofibromatosis type 1 locus. Cell 62:187-192.

43. Wallace, M. R., L. B. Andersen, A. M. Saulino, P. E. Gregory, T. W. Glover, and F. S. Collins. 1991. A de novo Alu insertion results in neurofibromatosis type 1. Nature (London) 353:864 866.

44. Wallace, M. R., D. A. Marchuk, L. B. Andersen, R. Letcher, H. Odeh, A. M. Saulino, J. W. Fountain, A. Brereton, J. Nicholson, A. L. Mitchell, B. H. Brownstein, and F. S. Collins. 1990. Type 1 neurofibromatosis gene: identification of a large transcript disrupted in three NF1 patients. Science 249:181-186.

45. Wang, Y., M. Boguski, L. Riggs, L. Rodgers, and M. Wigler. 1991. Sar1, a gene from Schizosaccharomyces pombe encoding a GAP-like protein that regulates ras1. Cell Regul. 2:453-465.

46. Xu, G., B. Lin, K. Tanaka, D. Dunn, D. Wood, R. Gesteland, R. White, R. Weiss, and F. Tamanoi. 1990. The catalytic domain of the neurofibromatosis type 1 gene product stimulates GTPase and complements ira mutants of $S$. cerevisiae. Cell 63:835-841.

47. Xu, G., P. O'Connell, D. Viskochil, R. Cawthon, M. Robertson, M. Culver, D. Dunn, J. Stevens, R. Gesteland, R. White, and R. Weiss. 1990. The neurofibromatosis type 1 gene encodes a protein related to GAP. Cell 62:599-608. 